\title{
Who Controls Digital Culture?
}

\author{
Mark Poster
}

"Sharing data is the beginning of humanity."

- SkipGates, TV ad for Linux

The Digital Millennium Copyright Act (DMCA) of 1998 is most often approached from the point of view of the contending agents: the Recording Industry Association of America (RIAA), the Motion Picture Association of America (MPAA), the Electronic Frontier Foundation (EFF), peer-to-peer file sharing program developers and users, lawyers on both sides of the question. Each of these social agents perceives the DMCA from the limits of its situated position and each party has some validity to the arguments it makes from that perspective. For many of these agents the question of copyright law is about the fate of the culture industries, those corporations that control the production, reproduction and distribution of texts, sounds and images. I shall introduce what I regard as a broader viewpoint: that of the citizen concerned about the general relation of new technologies and democracy, about the question of transculture in an age of globalization, and more broadly still about the long-term relation of human beings to information machines. As a media studies theorist and historian, I view the question of copyright also in terms of the changing nature of the producer and the consumer, about the character of our culture, and about the scope of democracy or the basic freedoms of the citizen. Ultimately the question that must be raised in connection with the DMCA is that of who controls cultural objects-one that goes to the heart of contemporary societies since they increasingly depend on information in a planetary context.[1]

Popular culture compulsively returns to the theme of the future direction of technology. Film after film depicts machines and humans in various conditions of struggle, cooperation, and symbiosis. Robots of course are a staple of Hollywood, especially since Blade Runner (1982). The recent and highly popular Matrix Trilogy problematizes not only machines but in particular the complex of information machines that constitute the Internet. A dialogue in the second film in the series, Matrix Reloaded (2003) broaches the question of humans and machines in a particularly exigent manner. The scene occurs at a moment in the film when the machines are about to attack the humans. Neo, the hero of the film played by Keanu Reeves, and Councilor Hamann, played by Anthony Zerba, emerge from an elevator that has descended into the engine room level of the humans' stronghold. The Councilor marvels at the complexity of the machines before them.

\footnotetext{
Councilor: Almost no one comes down here unless of course there's a problem. That's how it is with people: nobody cares how it works, as long as it works. I like it down here. I like to be reminded that the city survives because of these machines. These machines are keeping us alive while other machines are coming to kill us. Interesting isn't it? The power to give life and the power to end it.
}

Neo: Don't we have same power?

Councilor: I suppose we do. Sometimes down here I keep thinking about all those people still plugged into the matrix. And when I look at these machines, I can't help thinking that in a way we have plugged into them.

Neo: But we control these machines. They don't control us.

Councilor: Of course not. How could they? The idea is pure nonsense but it does make one wonder just, what is controlling? 
Neo: If we wanted, we could shut these machines down.

Councilor: Of course. That's it. You hit it. That's control isn't it? If we wanted we could smash them to bits. Although if we did we would have to consider what would happen to our lights, our heat, our air.

Neo: So we need machines and they need us. Is that your point, Councilor?

Councilor: No. No point. Old men like me don't bother with making points. There is no point.

Neo: Is that why there are no young men on the council?

Councilor: Good point.

Neo: Why don't you tell me what's on your mind councilor?

[Music begins suggesting the importance of the words that follow.]

Councilor: There is so much in this world that I do not understand. See that machine? It has something to do with recycling our water supply. I have absolutely no idea how it works. But I do understand the reason for it to work. I have absolutely no idea how you are able to do some of the things you do. But I believe there's a reason for that as well. I only hope we understand that reason before it's too late.

Today one might say we are in the same position as these humans of the future. We can turn off the machines off only at the risk of catastrophe, a condition that compels a rethinking of our relation to machines as one of agent to tool. In addition, many of the older generation - the Councilor Hamanns - have no idea what has become of the younger generation in its interactions with information machines, the virtual realities proliferating on the Internet. Yet there are clearly alternative approaches to this emerging digital culture and the direction we take in relation to it most likely will greatly affect the human condition for the next decades. The question then may be put as follows: Who controls digital culture?; Who ought to control digital culture?; and additionally, is control a good term to use in relation to digital culture?

\section{Controlling Information and its Hazards}

The case of the Soviet Union is instructive in this regard. This bureaucratic state abhorred the free flow of information and attempted to restrict technologies that promoted it such as photocopy machines, computers, and video cassette recorders (VCRs) for example. When the Soviet Union began to manufacture VCRs they excluded the capability of recording, limiting VCRs to playback machines, thereby imagining the government could control the reproduction and distribution of moving images. In their effort to control information, to keep information in the hands of the bureaucrats at designated levels of the hierarchy of the state apparatus, the Soviet political machine wrestled hopelessly with the increasing spread of machines throughout society that were capable of reproducing and disseminating texts, images, and sounds. As machine after machine was introduced as a consumer item, the Soviets attempted to control culture in the manner it was controlled by the Tsarist regime before the Revolution of 1917, at the beginning of socialist society. While the West especially after World War II increasingly integrated information machines at all levels of society and in all corners of everyday life-raising productivity with automation, empowering consumers against giant corporations like AT\&T with inexpensive telephones, promoting youth cultures with cheap radios, assisting in the proliferation of women's subcultures, ethnic communities, and groups with marginalized sexual orientations with electronic devices that preserve images and sounds - the Soviets resisted, fending off communications from the West as well as the information machines that promote the creation and distribution of culture beyond the control of the government. Some observers go so far as to attribute the collapse of the Soviet Union exactly to its defensive and futile policy of information control (Castells 1998).

The music industry (Recording Industry Association of America until 2003 represented by Hilary Rosen) and the film industry (with Jack Valenti as President of Motion Picture Association of America) reacted to the rapid spread of peer-to-peer file-sharing of music and films much in the manner of the Soviet bureaucracy, and, as far as one can tell at this point, with much the same effect. The culture industries attempted to destroy the new information 
machines. They lobbied hard for the passage of the DMCA. And they would have us believe the DMCA is about the author's rights: the compensation of creative people for their innovations. In their suit of September 2003 the RIAA has acted as if downloading music files is the same thing as taking a music CD from a retail store without paying for it. This claim of equivalence is a political move that ignores the specificity and differences of each media-CDs and digital files (Hull 2003). But if this were so, then the 12 year-old girl who was subpoenaed by the RIAA and settled the threatened suit out of court was capable of performing the same social functions as the music industry (i.e., copying and distributing music). And in that case, clearly, the music industry is superfluous and redundant, far less efficient than the girl who accomplishes the tasks at almost no cost.

If the case of the Soviet Union's effort to control information technocultures is instructive, so is the case of the copyists' assault on the print guilds in the fifteenth and sixteenth centuries. The resort to political institutions like the legislature and the judiciary by industries threatened by technical progress is not at all new. As Jacques Attali reports in Noise, one hundred fifty years after the origin of the printing press in Europe, copyists in France requested aid from the Parlement de Paris and received the right to destroy printing presses (Attali 1985)! The copyists had good arguments. They produced beautiful, illuminated manuscripts and codices. Their works compared very favorably in comparison to the fledgling print industry. During the period of the production of incunabula in the fifteenth and sixteenth century, few of the later conventions of page composition were in practice. Margins, word and line spacing, paragraph demarcations, the use of periods and commas - all of these commonplaces of the printed page that make it so readable were not yet in use. Early products of the print industry are ugly and difficult to scan. True enough the copyists made many errors and their work was unreliable because of this. But the early print industry, contrary to modern expectations about the consistency of the printing press in comparison with the scriptoria, also habitually made errors (Newman 1985). Authors had no assurance that their manuscripts would be faithfully reproduced by the Stationers' guilds. Hierarchies of status within the print guilds did not give pride of place to authors, who had not yet been elevated to the place of genius they would later enjoy. Instead masters and journeymen ruled the place of production. If journeyman compositors wished they simply altered the text to suit their sense of quality, the modern conception of the inviolability of the author's work, as well as the concomitant cultural fetish for a uniform text, were not yet inscribed in the practice of book-making (Johns 1998). When the French copyists received the go-ahead to destroy printing presses they easily identified themselves as the aggrieved parties with rectitude (and no doubt God) on their side just as the contemporary music industry ascribes to itself the defense of the artists and the rights of private property.

But there is an important distinction in the two cases: the feudal copyists' confrontation with the printing press was based on the preservation and authority of tradition; capitalism's confrontation with peer-to-peer networks is justified by its commitment to technical progress. If the music industry wins its case against internet technology, capitalism loses its legitimacy as the bearer of progress. The copyists did not have to defend themselves against the charge of holding back progress since no such ideological prescription prevailed. The music industry, on the contrary, must somehow show that progress is promoted by destroying an innovative and very promising information technology. They face an uphill battle, to put it mildly. In their defense, the music industry points to the fact that more music is available to consumers today than ever before. Their conclusion is that the current system works just fine and that peer-to-peer networks will diminish the amount of music in circulation. The argument from complacency echoes the copyists' plaint too closely. If the status quo ante prevailed in the fifteenth century and the printing presses were somehow destroyed, one cannot imagine the loss. The printers' argument that their machines were more efficient, would produce more books at a cheaper cost, and would be of benefit to more individuals, could not be proven in 1470. The same is true today: peer-to-peer file sharers cannot prove that a society without the RIAA will be better served than the current arrangement. These are counter-factual arguments that do not hold much water. Yet it is plain that a printing press works better than the human hand and that peer-to-peer networks are superior means of reproduction and distribution than Time-Warner and EMI corporate facilities[2]. And to take the argument beyond economic calculation to political effects, one might also say that printing democratized books by enabling individuals of modest means to purchase them, that it made universal education possible for the same reason and that, finally, it was a condition of possibility for the democratic citizen since reading is a prerequisite for independent political judgment. Similarly, one can argue that peer-to-peer networks will loosen the stranglehold of the music industry on the circulation of music allowing far more musicians to be heard than presently is the case, that it will foster a greater proliferation of music as a result. In addition, peer-to-peer networks, as we shall see promote the transformation and recirculation of music by the consumer, effectively laying the groundwork for the elevation of consumption into 
creativity, ending the bifurcation of production and consumption.

\section{The Politics of Control, or Politics as Control}

The Oxford English Dictionary provides several instructive definitions of control. As a noun, the primary definition of control is: "The fact of controlling, or of checking and directing action; the function or power of directing and regulating; domination, command, sway." As a verb, the definition is: "To check or verify, and hence to regulate." The OED has also updates to definition of the noun, control, as follows: "control freak orig. U.S., a person who demonstrates a need to exercise tight control over his or her surroundings, behavior, or appearance, especially. by assuming command of any situation or exerting authority over others." The OED does not, of course, explore the question of the subject of control (What kind of agent has or seeks control?), nor that of the culture of control (To what extent is control by agents important to a culture? and, more significantly, What is the nature of the subjects and objects in the culture that do the controlling or are regulated by such agents?) These questions animate my analysis of the music industry's relation to the innovation of digital technology. The numerous studies that raise the question of control in relation to digital media tend to assume that individual or collective agents are in positions of control or lack of control. They define the question as one of who ought to control the technology, never asking the more basic question "Is control by agents the best way critically to understand the general relation of digital technoculture to control? Do digital media support enhance or undermine practices of control?’'[3]

In the case of the DMCA, the music industry attempts to maintain control over their product in the face of the new technology of digital reproduction. I argue that the main issue in the enactment of the DMCA is the control of cultural objects. Digitalization has radically altered the conditions of culture. In response, the RIAA has exerted enormous influence on politicians to pass laws, including the DMCA, to extend copyright to cover digital products. In this way the RIAA hopes to maintain control over cultural objects. It is often argued that the introduction of new technologies is accompanied by disruptions to the existing order of control, eliciting great expectations that democracy, peace and freedom will thereby be enhanced (Marvin 1988). Most historians of technology, however, contend that as the new technology is disseminated throughout society and is assimilated into it, controlling agents that preexisted the innovation soon regain their dominance (McCourt and Burkart 2003). This view, I argue, is blind to the manner in which information technologies alter both culture and society. Even if dominant institutions are not directly overthrown by new technologies, fundamental aspects of culture are indeed transformed by them. This argument cannot be developed here although it has been posited by many leading media theorists and historians (McLuhan 1964; Adorno 1972; Heidegger 1977; Kittler 1986; Baudrillard 1994; Manovich 2001; Poster 2001). What I do want to avoid, however, is the premature conclusion that peer-to-peer file sharing will quickly be either eliminated or adapted by the RIAA.

Two observations about the introduction of new technologies are pertinent at this point. First, the relation of a technology to social practice is a complex, changing phenomenon that is not reducible to the goals of its developer. The inventors of audio recording (Edison's phonograph), for instance, intended the device for the preservation of voice (Sterne 2003); yet, the technology eventually became a means of mass producing copies of music (Attali 1985). The conclusion one must draw from this case is that new technologies lead to disruptions of old ways of doing things - disruptions that are unanticipated and unpredictable — and so it has been and will continue to be with networked computing. The intended uses of the computer were to further social controls by the elite (ensure communications under conditions of nuclear war); the outcome may be the overturning of certain systems of social control (i.e., the culture industry) (Attali 1985).

The second observation is this: Digitization has thus far produced strong tendencies in two opposite directions concerning the question of the control of culture:

Digital culture enhances the ability of large institutions, such as the state and the corporation, to extend the reach of their information and management of the population. In the case of music, the culture industry has responded to digitalization by attempting to extend its control over culture, attempting to limit sharply the ability of consumers to use cultural objects as they wish.

At the same time, digital culture empowers individuals to have positions of speech that are difficult to monitor, to act upon cultural objects in ways not possible when these objects were available only in analogue form, to transform, reproduce and 
disseminate information in a manner previously restricted to expensive central apparatuses such as broadcast facilities. Because of the ease and cheapness of the creation, reproduction and distribution of cultural objects, users have extended their control over cultural objects such as by sharing files on peer-to-peer networks.

Networked computing confronts humanity with a dramatic choice of opposing possibilities: an Orwellian extension of governmental and corporate controls or a serious deepening of the democratization of culture. In this context, the most important question to ask about the DMCA is how society will establish practices around the digitalization of cultural objects. Will it follow (1) the wishes of the culture industry, or (2) the practices exemplified in peer-to-peer networks, or (3) some combination of the two, or (4) the impulses of some other set of agents?

\section{Fixed vs. Variable Cultural Objects}

On February 10, 2004 The Los Angeles Times reported that EMI blocked Brian Burton (also known as DJ Danger Mouse) from distributing "The Grey Album," a composite blend (a "mash-up" or sampling) of the Beatle's White Album and vocals from Jay-Z's "The Black Album." EMI's attempt to prevent the distribution of the album failed, only increasing its dissemination. Fred Goldring, a music-industry lawyer opines: EMI “...created their own hell.” The Grey Album, the reporters continued, “... became probably the most widely downloaded underground indie record, without radio or TV coverage, ever. I think it's a watershed event." (Healey and Cromelin 2004). The protest against EMI included "Grey Tuesday" (February 24th) when more than 150 websites offered downloadable versions of the album and an estimated 100,000 copies were downloaded on that day alone. Copyright experts observe that “artists can't use a recognizable sample from someone else's recording unless the copyright holder grants permission" (Healey and Cromelin 2004). Goldring claims that "artists should have the absolute right to control their work. The problem is, how do you control that in the new world?... [But] what does [it mean to control one's work] in a world where everything can be digitized and transmitted around the world at the push of a button?" (Healey and Cromelin 2004).

EMI's action continues the effort of the music industry to repress sampling, an art form begun in the $1980 \mathrm{~s}$ with Hip Hop. Many artists advocate, contra EMI, “open content” in digital culture, some who even elaborate an aesthetic based on the principle of variable cultural objects (Miller 2004). Artists who have authorized the downloading, altering and redistributing of their work include Bjork, Moby, Radiohead (posting loops on their website for downloading and using in other works) and Public Enemy "....allowing access to original master tracks of the vocals for open remixing..." (Vibe 2004)

Modern society developed in the context fixed cultural objects like books. These objects may be owned but they cannot be changed once they are produced. If they are altered, the user can alter only his or her copy. All previous and future copies are not affected by the alterations of the user. This is a limitation of analogue cultural objects. They can be mass-produced but only from fixed points of production, points that require great amounts of resources. The user cannot copy these objects in a mass form. This feature of cultural objects, their fixity, has had the further consequence of structuring society into two sharply divided groups, producers and consumers, each with their own capacities and limitations. Consumers were in a relatively passive position in relation to the objects.

Another feature of modern media culture is that, since reproduction required considerable resources, copies became commodities, that is to say, they were distributed through market mechanisms and acquired exchange values or prices. Analogue reproduction of cultural objects thus requires a type of material base that falls under the economics of scarcity. Air does not require a market because it is not scarce, at least if you live near the beach. Scarcity means that a group of people are willing to pay for an object or service because that is the only way they can obtain it. They go to a market to find these objects and the price of the objects will reflect the ratio of the number of these objects available and the number of buyers who can pay for them. The economics of scarcity also means that if I sell you an object, I no longer possess it. Only one person may own a given object at any time.

Fixed cultural objects like books afforded certain advantages to consumers. The consumer, having bought the book, could read it anywhere he or she chose. The consumer could lend the book to a friend or resell it. The consumer could copy the book by handwriting and later by photocopying machines, which, though illegal, is impossible to police. The consumer could burn the book or throw it in the trash.

Digital cultural objects do not fall under the laws of scarcity and the market because they require almost no cost to produce, to copy and to distribute, and like ideas they do not diminish when they are given away. They 
are "nonrivalrous." There is no need for a capitalist market in the area of digital cultural objects and these objects need not become commodities. Their reproduction and distribution need not fall under the constraints of scarcity economics and indeed digital cultural objects resist market mechanisms.

Digitalization of cultural objects changes each of these limitations or practices and expands the possible practices of analogue cultural objects concerning their production, reproduction, distribution and use. It enables the inexpensive production of cultural objects such as sound recordings or moving images. It places in the hands of the consumer the ability to reproduce these objects very cheaply. And digital networks enable consumers to distribute cheaply cultural objects. It also enables the consumer of cultural objects to change them into new objects and to reproduce and to distribute them. Digitization also means the object is more difficult to destroy since it exists on the Internet. In short it changes the nature of the producer and the consumer, blurring the boundary between them. The consumer can now be a producer, reproducer, distributor, and creator of cultural objects. Thereby digital technology undermines the systems of controls that were associated with fixed cultural objects and brings control of culture itself into question by opening cultural objects to an unlimited process of alterations.

\section{Copyright Law}

The DMCA act (1998) extends the copyright law over analogue cultural objects to cover digital cultural objects, defined as texts, sounds, and images. Its main provision is to outlaw the "circumvention of technological measures used by copyright owners to protect their works and ... tampering with copyright management information." (The Digital Millennium Copyright Act of 1998: U.S. Copyright Office Summary, p. 1). Thus programs designed to defeat copy protection (such as DeCSS and software that cancels the regional limitation DVD players are now illegal both to create and to distribute.

The 1998 law also aligns U.S. copyright law with recent agreements of the World Intellectual Property Organization acts. In addition it establishes ISPs as "safe harbors" in the sense that ISPs cannot be held liable for users' infringements but the ISP must enforce the rules against infringement and the RIAA is permitted to subpoena users.

One provision of the law [Section 512(h) of the DMCA (17 U.S.C. 512)] gives copyright claimants the right to subpoena ISPs for the identities (name, address, email address, phone) of users they allege are infringing their copyrights. It does not, however, let claimants of infringement get other information about user activity. The RIAA has until as of March 2004 used these subpoenas (almost 3000 to sue 382 individuals) to force ISPs to turn over the names of alleged filesharers, so the record labels can turn around and sue their fans.[4]

A U.S. Court of Appeals, however, ruled in December 2003 that the Recording Industry Association of America cannot use subpoenas to compel ISPs to reveal the names of alleged music file swappers. The RIAA may only obtain a subpoena from a U.S. District Court clerk's office after proving to a judge that it has sufficient evidence of infringement.[5] Finally, the DMCA provides for some exceptions, such as when a computer breaks down.[6]

Copyright laws were enacted in the late seventeenth and early-eighteenth centuries first in Britain, then in the U.S. and Western Europe as a response to the new technology of the printing press that made possible the mass reproduction of text (Rose 1993). Copyright law is associated with patent law and trademark law but is somewhat different from them. Copyright law covered the medium in which inventions or acts of genius were embedded for reproduction. The medium of print required advanced technology and copyright law forbad anyone not authorized to use that technology for reproducing books and selling them.

Until the mid-twentieth century, copyright gave "authors" a monopoly over their innovations for about 17 years but numerous changes in the law extends this to about 100 years and includes the descendants of authors.

Original copyright law also ensured that "readers" had rights such as "fair use" - the right to quote a work in order to critique it or make fun of it. This provision has been seriously curtailed by the DMCA. Proposals by Microsoft and the culture industries known as Digital Rights Management and Trusted Computing would do away with much of fair use.

Copyright was adapted to new technologies of reproduction as they were invented and distributed in the areas of sound (the music industry, radio) and images (photography, film and television). In each case the rights of authors were whittled away in favor of control by media industries (Lury 1993). Each new technology changed the circumstances of reproduction, changed the medium in which the cultural object was embedded and placed on the 
market, and called for changes in the nature and application of copyright law. For example, copyright law did not explicitly prohibit consumers from making copies (you will not find such a prohibition in books and they only were printed on LP labels after the spread of audio tape machines) because consumers did not have the capability of doing this in the media of print, film, early audio recordings, and so on.

In general one can say that, as reproducers of cultural objects became larger due in part to the need for greater amounts of capital, copyright law increasingly diminished the power of the author/creator and increasingly reduced the rights and capacities of the consumer in both cases in favor of the media corporation (Vaidhyanathan 2001). Copyright law is the chief means by which large corporations in general and music firms in particular attempt to control culture. In the words of Kimbrew McLeod, “....intellectual property law reinforces a condition whereby individuals and corporations with greater access to capital can maintain and increase unequal social relations" (McLeod 2001). Corporations use the threat of legal action systematically to stifle creativity even when the incident in question may fall fully within the "fair use" doctrine. The system of copyright law is so far out of whack that countless examples, such as Time-Warner's ownership of the song "Happy Birthday to You," force the conclusion that, with regard to intellectual property, the legal structure no longer provides any semblance of justice. Hence all citizens have an obligation to violate copyright law whenever they can. Since the legislative branch of government is under the sway of the media industry, the only alternative available to foster democracy and promote creativity in the realm of culture is Henry David Thoreau's practice of civil disobedience. And digital technology has provided citizens with a practical means to carry out this protest. Digitization threatens the media corporations because one no longer requires great amounts of capital in order to produce, reproduce, modify, and distribute cultural objects

\section{Authors, Artists, Creators, Innovators}

Contra the music and film industries, copyright is not about remuneration for artists, authors, creators and innovators, much less their heirs. Copyright was instituted to promote innovation in society, to improve the quality of life for all. In order to do that copyright provides a temporary monopoly for authors to designate firms to reproduce and distribute their work. The argument in copyright law is that the best way to insure the advance of science and the arts is to violate free market principles of competition and give authors the exclusive right to receive monetary rewards for their efforts. What benefits society is the innovation or creativity that is contained in the cultural object. Essential to democracy is the maximum dissemination of new ideas, new science and new art. Original copyright laws foster this aim.

Contemporary copyright law, especially as modified by the DMCA, (mis)uses the privilege given to the artist and instead enables the cultural industry to reap large gains. Only as a secondary result of the current arrangements do some artists receive substantial royalties. (Many artists have sued the music industry, claiming systematic underpayment or cheating, and won in the courts.)

The music industry argues against peer-to-peer file sharing that such transmissions violate the artists' royalty benefits. There is no question but that file sharing bypasses author's royalties. But the question is how to remunerate innovators in a digital network system. And the answer is by no means that the network must be crippled so that the music industry continues to perform functions of reproduction and distribution that are no longer wanted or needed. There are three problems I shall highlight concerning the question of author royalties in the age of file sharing.

First, it is by no means to be taken as a natural fact or a universal truth that artists and innovators receive compensation for the reproduction of their works. Each medium and art form is different in this regard. Musicians, for instance, certainly ought to be paid for their performances. Musicians' Unions have in some instances opposed recordings of music, especially when used in public locations like dance halls.[7] But who should be compensated for music in the case of reproduction technologies? Perhaps the engineers, the inventors of these technologies, ought to be paid royalties. The case of library collections of music remains apposite: borrowers of music CDs do not pay royalties to anyone so that no one is compensated yet the public good is served.

By way of contrast with the music industry, it is worth noting that in the case of film, cinemas provide a value added to the moving images/sound by displaying them in convenient locations, in comfortable circumstances, and on very large screens often with elaborate sound systems. Such enhancements to the film experience are worth compensation. Although the advent of HDTV and large screen TV monitors in home entertainment systems may 
challenge cinemas on this score, at least for those who can afford them. The film industry has to some extent learned a lesson from the experience of the music industry. The MPAA hired Kenneth Jacobson, former FBI agent, to head its antipiracy efforts, who complained that downloading films on the Internet cut sharply the sales of DVDs and tapes. Yet the more serious aspect of film piracy concerns the unauthorized copying and selling of DVDs, according to Jacobson, amounting to more than 35 million in 2001. In some countries, he contended, "film piracy has become so rampant in countries such as China, Russia and Pakistan that the legal markets there have all but evaporated" (Muñoz and Healey 2001).

Second, file sharing, unlike some forms of so-called piracy does not entail the sale of commodities. File sharing is a non-market exchange. It is not similar to early piracy in print where shops would reproduce books and sell them without authorization from or compensation to the author. Nor is it similar to Asian factories that copy CDs and DVDs and sell them cheaply in local markets. In fact digitalization enables costless sharing of cultural objects. It resembles not violations of copyright but playing music in one's home with friends in attendance, friends who themselves did not necessarily buy the cultural object. One must account for the specificity of the medium of reproduction: digital reproduction, I would argue, does not fall within copyright at all because the kind of materiality of digital files is not characterized by the economics of scarcity. Unlike books, films and broadcasts, with digital media, unless commodified, there is nothing to pay for.

Third, artists have always incurred debts to others. They are not the complete originators of works of art as copyright law pretends but, at least partially, parasites that rely upon previous cultural creations, collaborators, and workers in related fields. Arts works are as much or more the product of collective labor as they are the output of individual agents. No other culture in human history but the modern Western one has detached artists from their context and elevated them in sanctified celebrity. But this cultural practice defies the history of art, with its figures like Rubens who painted only with a large staff of specialists and film-making with its numerous casts of participants. The collective nature of the creative process is nowhere more evident than in music, from the borrowing practices of Handel and Vivaldi, to the "coverings" of popular music as in Bob Dylan's reliance upon Woodie Guthrie, to the outright montage-like pasting of bits of works in hip hop and the practices of DJs (Hebdige 1987; Poschardt 1998). Art requires a cultural context of other art, numerous collaborators, and media producers. It also, let us not forget, requires audiences.

The figure of the artist as lone creator is today more than fiction serving the music industry as an alibi to abet its control of culture. With the increasing shift to digital culture, artworks, as we have seen, more and more take the form of variable cultural objects, in short, open content. The culture industries, as they have come to be institutionalized, cannot exist if cultural forms are developed as variable objects. Peer-to-peer file sharing is an important step in the articulation and elaboration of culture as open content.

For these reasons the question of file sharing is not as simple as the music industry would have us believe. A full understanding of the question requires some knowledge of the current practices of file sharing. To that end, I shall now present an overview of peer-to-peer file-sharing networks.

\section{Peer-to-Peer Networks}

Most discussions of the current condition of music distribution and file-sharing begin and end with Napster (Lessig 1999). Observers presume that the fate of file-sharing on the Net rests with Napster. Since Napster was forced to shut down as a free network only to reemerge reborn, like the Phoenix, as a .com venture, these writers close the curtain on file-sharing. Of late, some writers throw KaZaA into the mix but again conclude that since shared files have decreased recently from a high of $900,000,000$ to 550,000,000, the era of the free distribution of music on the Internet is over[8]. But such is hardly the case. A robust, heterogeneous matrix of file-sharing continues and evolves.

The circumstances of my own knowledge of file sharing are germane to this discussion. I first became aware of file-sharing in the Spring 1999 when I taught a class on Internet Culture and learned of file sharing from my undergraduate students. Students were asked to present brief reports on their favorite web sites. One student spoke about "Scour.net," a web site that contained links to downloadable mp3 music files. Even before Scour, fileswapping was rampant on Internet Relay Chat and Usenet. But it is true that Napster vastly expanded the frequency of file-sharing by its peer-to-peer architecture and ease of use. Shawn Fanning's program was vulnerable to legal 
attack because a central location maintained a database of files, acting as a server for clients who used the program to find music to download. The newer "killer applications" do not suffer this weakness. Programs like KaZaA and Justin Frankel's Gnutella for instance enable each user to make their own connections with other peers, coming much closer to a true peer-to-peer connection. One can find an overview of the many types of file-sharing programs and networks on sites like Slyck (http://www.slyck.com/).

The most basic network for file-sharing remains Internet Relay Chat (IRC). Here, after invoking a client program, one makes direct connections with others and exchanges files while both parties remain online. There are also more elaborate subnetworks within the IRC domain. As long as the Internet functions as a decentralized system of networked computers, IRC will be difficult to police since there are no centralized sites to shut down. IRC however does suffer the limitation of scale: it does not provide the kind of networked information that facilitates mass interchange of information.

The next type of file-sharing occurs on Usenet, also known as Newsgroups. The original purpose of Usenet was the exchange of textual information, which was also true of IRC. For some time now, users developed methods of dividing up large music and even film files into chunks small enough to meet the size limitations of the Usenet system. These files are known as binaries and are bundled into groups. One downloads all of the parts and then reassembles them on one's computer, resulting in an mp3 file for music, a jpg file for images, or, for moving images, an avi file. Users then developed downloading programs that automatically assemble the parts into complete files. One difficulty with Usenet is the problem of finding the cultural object one is looking for amidst the profusion of thousands of groups. Faced with this limitation, users developed web sites where other users upload reports on each group, indicating the available content. This is done continuously, day after day. As with IRC, it is hard to imagine how Usenet might be policed. Usenet services contain the files but downloaders simply indicate their choices, as one would do at a File Transfer Protocol (FTP) site. No record is kept of who downloads what files. The shortcoming of Usenet is that the files are available for a limited time only, since the content of the groups changes every couple of days.

More popular than Usenet or IRC are the numerous networks like KaZaA that deploy genuine peer-to-peer programs. Among these are the eDonkey and eMule networks. In these cases each cultural object is assigned a "hash" number, a long string of letters and numerals that identifies the film, game, ebook, program, or music album to all users connected to the network. The hash numbers are posted, under the file name, at numerous sites on the Web. The user goes to the site, clicks on the file name and the client program pops up on the user's computer and searches the network for locations where the file exists. The program then downloads the file in small parts from several sites at the same time, something Napster could not do. Nor could Napster resume downloading if the site in question went offline or the user went offline, a feat the newer programs perform flawlessly. Finally the program assembles the parts into a complete file when it is finished with the download. While you are downloading a file or several files with eMule, others on the network are uploading the same file(s) from your computer. These complex, interlocking web sites and programs are all free and developed (and continuously improved) by individual file-sharers.

Another, somewhat different system is Bram Cohen's Bit Torrent. This program also uses identifiers for files so that the location that contains information about the file does not contain the file itself. Like the KaZaA and eDonkey systems, Bit Torrent allows multiple, simultaneous downloading of parts of a file. With Bit Torrent, a separate window opens for each download and uploads are limited to the file being downloaded.

Thousands of individuals create programs, maintain web sites, upload hash numbers of "releases" (cultural content they have digitized and put on their hard disks) and hundreds of thousands, more likely millions, download and share files. Participants in peer-to-peer networks are found across the globe although numbers of users are no doubt distributed in direct proportion to general Internet use. The peer-to-peer landscape is maintained as a public sphere outside the commodity system. Some sites do request donations that are voluntary. A distribution system for cultural objects thus subsists without the support of any large institution and with the strong opposition of those corporations that have controlled cultural objects since the development of technologies for the reproduction of information. Despite the moral and legal threats and actions of the MPAA and RIAA, peer-to-peer file-sharing continues to flourish and even to expand. It seems that publicity about each new attack by the culture industries only makes more people aware of the peer-to-peer network and increases the number of participants. As one says in the movie business, no publicity is bad publicity for peer-to-peer networks.

Even as one marvels at the accomplishments of the peer-to-peer system, one may question the moral value of sharing cultural content. Surely downloading files is not a great creative act. Nor however is buying a CD in a 
retail outlet, it must be admitted. One question at stake in the peer-to-peer phenomenon is the value one attributes to commodity exchange in comparison to sharing. But a deeper question still is the potential of peer-to-peer to become a dominant system of cultural exchange. An infrastructure is being set into place for a day when cultural objects will become variable and users will become creators as well. Such an outcome is not just around the corner since for generations the population has been accustomed to fixed cultural objects. But as we pass beyond the limits of modern culture, with its standardized, mass produced consumer culture, we can anticipate more and more individuals and groups taking advantage of the facility with which digital cultural objects are changed, stored, and distributed in the network. A different sort of public space from that of modernity is emerging, a heterotopia in Foucault's term (Foucault 1986), and peer-to-peer networks constitute an important ingredient in that development, one worthy of safeguarding and promoting for that reason alone. If copyright laws need to be changed and media corporations need to disappear or transform themselves, this result must be evaluated in relation to a new regime of culture that is now possible. In considering the alternatives, let us take the example of the music industry examine its claim to foster cultural innovation and democracy.

\section{The Music Industry}

This sector of the culture industry has been exceptionally destructive in its appropriation of copyright law. One can surmise, referring back to the OED definitions of "control" that the RIAA qualifies as a "control freak." Here are just some of the ways the RIAA has worked to redefine copyright law (and the law in general in relation to the music industry) to maintain and to extend its control over popular music:

The RIAA influenced legislatures through campaign contributions to make exceptions to laws governing labor contracts so that it could require artists to sign long term contracts for five to seven albums. When these statutes are not as favorable as the RIAA wishes, it manipulates the contract to extend its control over artists. Typically, the contract specifies that the music corporation has exclusive rights to the artists' future work. The corporation lengthens this contract for a number of years by spacing out the production of albums, arguing that this is the best marketing strategy. The music corporations habitually delay the production of albums to suit their marketing interests, thereby in fact, holding the artists under their contract for as long as the corporation wishes. This practice constitutes one of the few legal examples of indentured servitude in modern society (professional sports being another) (Shemel and Krasilovsky 1990).

The contracts with artists require artists to pay for the production of the music media (studio time, etc.), the design and packaging of CDs (about 25\% of the retail price), and returns (about 10\% of gross receipts). All of these costs are treated either as advances on royalties or deductions from royalties. The corporations essentially are limited to marketing the product and the Internet represents a form of distribution they do no control. The vast majority of artists never see a penny from the sale of their music. In fact, one critic reports "the record industry acknowledges that less than 10\% of its artists will 'recoup' or make back, the advances they're given when they sign a recording contract." (Wilcom 2003).

The music industry has corrupted the system of music distribution in several ways, some of which are:

a. It paid off radio disk jockeys to play its music, a practice known as payola, now a general term for bribery. The practice of paying for the performance of music began as early as the 1880s, but only after World War II did the payments go to radio djs with the "scandal" of exposure occurring in the late 1950s. Payola continues to be practiced today although on an informal, under-the-table basis (Segrave 1994).

b. It successfully destroyed the Digital Audio Tape format for home consumption in the 1990s. The RIAA pressured Congress to pass the Audio Home Recording Act of 1992 which mandated the inclusion of copy controls that prevented making more than one copy of a tape. DAT also recorded at frequencies incompatible with those of standard compact discs, $48 \mathrm{kHz}$ instead of $44 \mathrm{kHz}$. A superior consumer technology was thus destroyed by the music industry, indicating once again the incompatibility of technical advances with corporate controls.

c. It forced retail stores to maintain high prices for CDs, a practice that in May 2000 was ruled illegal by the Federal Trade Commission and subsequently by the courts (in an out of court settlement in 2002). In this case the music industry's monopolistic practice was aborted by the political system.

The concentration of the music industry to five major labels (Bertelsmann, EMI, Sony, Time Warner and Universal) has facilitated its control over artists, distributors, and consumers. In parallel with trends in other 
media industries, the music industry has consolidated into an oligopoly structure that restrains innovation and stifles diversity in culture.[9] These companies have accounted for over $80 \%$ of the world-wide sales of recorded music (Negus 1999).

The music industry has not given royalties to artists from the sale of work distributed through the Internet. At the height of the controversy over the Napster file-sharing program, Hilary Rosen, speaking for the RIAA, proclaimed the moral superiority of the music industry over online "pirates" in protecting artists' rights while at the same time denying artists payment for the copies of music enabled by networked computing.

The music industry's response to file-sharing has been "lawsuits, draconian legislative initiatives that trample on people's fair-use rights, and threats of invasive actions against the very people who buy their products." (Wilcox 2003) In 2003 a computer company (Apple) began experimenting with distribution of music over the Internet. While costs of reproduction approach zero, Apple charges an exorbitant $\$ 1$ for each song downloaded. It remains to be seen if the music industry can develop a viable business model in the age of digital reproduction and peer-to-peer distribution.

Most methods developed or imagined by the music industry to regain control of what they think of as "their product" involve crippling the technologies of networked computing. Introducing watermarks in files, threatening ISPs with lawsuits, defeating digital reproduction, including terminal dates or number of uses into music files, preventing audio CDs from playing on computers, sending out review copies in locked CD players, and so on. Here capitalism is directly in opposition to promoting progress in technology, a situation that is the complete reverse of its history during the Industrial Revolution and its legitmation by economic theorists like Adam Smith as the economic system most conducive to the progress of humanity and its material well-being. The conclusion is clear that the music industry has corrupted the democratic process of legislatures, the artistic process of music making, the distribution system of radio, CD and DAT sales, and the new technology of peer-to-peer file-sharing on computer networks. If anyone has a high moral ground in the area of cultural objects it is not the music industry. When they speak of piracy, we must add that property in the case of the music industry, to quote Pierre-Joseph Proudhon, is theft.

\section{The Politics of Digital Music}

I prefer to analyze the contemporary situation not as an ethical problem, but as a political one: who shall benefit from the technical advances afforded by digitalization? What limitations have to be imposed on the rest of society in order for the culture industry to maintain its predigital controls over cultural objects? Is this sacrifice worth it? Can capitalism continue to be legitimized in the area of cultural objects, if the technological advance of networked computing are held back in order to preserve the music industry in its current form?

In addition to corrupting our political process, the artist, the distribution media, retarding technical advances and delegitimizing capitalism, the music industry, to maintain its present degree of control over culture, would require new levels of surveillance over individuals that would seriously impinge on privacy (compelling ISPs to monitor their customer's downloads), reduce the scope of civil rights, and generally debase the basic freedoms of citizens. How is this so?

The beginnings of this process date back at least to the Bangermann white paper on copyright prepared for the World Intellectual Property Organization meeting in the mid-1990s. At the time the music industry was clueless about the implications of networked computing for their industry. The Clinton administration however was one degree less clueless. The Bangermann report attempted to impose U.S. copyright standards on the world and to extend those standards to include digital technology. It seriously proposed that every copy of every cultural object fall under copyright law, meaning that if you copy an email from RAM to your hard disk that qualifies as a copy; if you copy from your hard disk to a floppy disk, this act also constitutes the act of copying. If you send a copy of a file to someone else, that also falls under the law. Each of these is a violation of copyright when the content has been copyrighted.

Why did the Clinton administration propose such an impossible expansion of intellectual property? For one reason, they made the proposal because cultural objects are second only to defense in export value of the U.S. A second reason is that the politicians were not aware that networked computing integrates copying within its functions and structures. Copying is automatic and continuous on the Internet. File Transfer Protocol, for example, is a basic function of digital networks. Copying is essential to the institutions of higher learning which developed 
networked computer. It represents a basic condition for intellectual freedom, scientific advance, and critical thinking. The Clinton administration easily trampled these hallmarks of a free society simply for the economic gain of some wealthy groups. The music industry, when it finally woke up and recognized the powers of peer-to-peer programs, was even more eager to destroy these features of our institutions.

Institutions of higher learning, have been, I am sorry to say, intimidated by the music industry's threats of legal action. They have far too often put serious restrictions on the free flow of digital information. Some universities have resisted. The best example is MIT which until 2003 imposed no restrictions. The worst example is Columbia University, which, according to Wired, "Monitors Internet use and kicks students off the network if they download more than 1 M[ega]bit per second for 10 minutes or longer.” (11:06 June 2003, p. 36). In the Fall of 2003, many universities were adopting pay-for-use music services and charging students for this (Harmon 2003). A joint committee has been formed (Joint Committee of Higher Education and the Entertainment Industries) to develop a compromise on downloading of music files through university servers, although the RIAA continues to seek legal remedies that would violate such agreements, such as lobbying for a bill in Congress, HR 2517, the Piracy Deterrence and Education Act. Universities are committee to the free and open exchange of information, while the RIAA is determined to survive regardless of the cost to the rest of society.

\section{Conclusion: Alternatives to File Sharing?}

By 2004 commercial alternatives to file sharing had emerged. The music industry's efforts in this regard however were weak and relatively unsuccessful. The Apple Corporation's iTunes provided the first viable downloading website for music, charging at first one dollar per song, then, as competition arose, less than 80 cents. But a Russian site, allofmp3.com, charged a mere 3.5 cents per song or .01 cent per megabyte[10]. Sites also appeared that allowed musicians to bypass the music industry completely, selling albums directly to consumers.[11] These are just example of commercial applications of music downloading that have successfully adapted the network to ideas developed in peer-to-peer networks. It remains to see to what extent they displace file sharing or become the new means of acquiring music.

We are clearly at a crossroads with regard to culture under the legal regime of intellectual property law. It behooves the university, users/consumers and others to resist the efforts of the culture industry in restricting the development of the digital domain. I argue we must not frame this resistance in terms of copyright law but in term of media of culture. We must invent an entirely new copyright law that rewards cultural creation but also fosters new forms of use/consumption and does not inhibit the development of new forms of digital cultural exchange that explore the new fluidity of texts, images and sounds. The issue of the control of culture must be framed in relation to the kinds of subjects and identities it promotes. Digital cultural objects enable the constitution of subjects in broader and more heterogeneous forms than modern culture with its fixed objects and delimited identities. At stake in the evolution of file sharing and other features of networked computing is a new culture of mobile and fluid selves, ones less beholden to the constraints of modern and even postmodern subject positions. Such a culture of the self is well adapted to encounter in a propitious manner the two great historical tendencies of the twenty first century: the emergence of intensified global exchanges of a transnational kind and the appearance of a new integration of humans and machines. These developments are not to be understood as utopian dreams but as the actuality we face. The salient question is "What will be our cultural resources in the confrontation of this fateful event?"

\section{Endnotes}

1. For a similar argument see Gillespie, T. 2004. "Copyright and Commerce: The DMCA, Trusted Systems, and the Stabilization of Distribution." The Information Society 20:239-254.
2. The class work on the history of the music industry since its inception is Sanjek, R. 1988. American Popular Music and Its Business: The First Four Hundred Years. New York: Oxford University Press. 
3. Two studies stand out on the question of control: Beniger, J. 1986. The Control Revolution: Technological and Economic Origins of the Information Society. Cambridge: Harvard University Press and Kelly, K. 1994. Out of Control: The New Biology of Machines, Social Systems and the Economic World. Cambridge: Perseus Books. /rhe former taking the position that digital technology furthers control by large corporations; the latter that this same technology undermines it.

4. Personal email from Wendy Seltzer (lawyer for the Electronic Frontier Foundation) December 1, 2003.

5. OpEd, Los Angeles Times, January 3, 2004, p. B14.

6. A full analysis of the legal aspects of the DMCA is expounded well in Lessig, Lawrence.2001. The Future of Ideas and Code and Other Laws of Cyberspace. See also Lessig, Lawrence. 2001. The Future of Ideas: The Fate of the Commons in a Connected World. New York: Vintage.

7. See Thornton, S. 1996. Club Cultures: Music, Media and Subcultural Capital. Hanover: Wesleyan University Press for a discussion of the resistance of the Musicans'
Union in England to the use of recordings in dance halls.

8. A study by economists in 2004 disputes the claim of the RIAA that sales have been adversely affected by filesharing. Felix Oberholzer-Gee of the Harvard Business School and Koleman S. Strumpf of the University of North Carolina at Chapel Hill maintain that filesharing has no measurable effect on sales of CDs. They suppose that downloaders would not buy the CD they are obtaining from peer-to-peer networks. Schwartz, J. 2004. "A Heretical View of File Sharing." New York Times.

9. For a history of this consolidation up through the mid-1970s and its influence on popular music see Chapple, S. and R. Garofalo. 1977. Rock 'N' Roll is Here to Pay. Chicago: Nelson-Hall.

10. I am grateful to Jamie Poster for alerting me to this site.

11. See for example http://www.cdbaby.com/ where artists sell CDs on the Web they make themselves. Garrett Wolfe informed me of this site.

\section{References}

Adorno, T. 1972. Dialectic of Enlightenment. New York: Continuum.

Attali, J. 1985. Noise: The Political Economy of Music. Minneapolis: University of Minnesota Press.

Baudrillard, J. 1994. Simulacra and Simulation. Ann Arbor: University of Michigan Press.

Beniger, J. 1986. The Control Revolution: Technological and Economic Origins of the Information Society. Cambridge: Harvard University Press.

Castells, M. 1998. End of Millennium. Malden, MA: Blackwell Publishers.

Chapple, S. and R. Garofalo 1977. Rock 'N' Roll is Here to Pay. Chicago: Nelson-Hall.

Foucault, M. 1986. "Of Other Spaces." Diacritics (Spring):22-27. Gillespie, T. 2004. "Copyright and Commerce: The DMCA, Trusted Systems, and the Stabilization of Distribution.” The Information Society 20:239-254.

Harmon, A. 2003. "Penn State Will Pay to Allow Students to Download Music." New York Times.

Healey, J. and R. Cromelin 2004. "When Copyright Law Meets the 'Mash-up." Los Angeles Times, pp. E1, E43.

Hebdige, D. 1987. Cut 'N' Mix: Culture, Identity and Caribbean Music. New York: Methuen.

Heidegger, M. 1977. The Question Concerning Technology and Other Essays. New York: Harper and Row.

Hull, G. 2003. "Digital Copyright and the Possibility of Pure Law." Qui Parle 14: 21-48.

Johns, A. 1998. The Nature of the Book: Print and Knowledge in the Making. Chicago: University of Chicago Press.
Kelly, K. 1994. Out of Control: The New Biology of Machines, Social Systems and the Economic World. Cambridge: Perseus Books.

Kittler, F. A. 1986. Grammophon, Film, Typewriter. Berlin, Brinkmann and Bose.

Lessig, L. 1999. Code and Other Laws of Cyberspace. New York: Basic Books.

-----. 2001. The Future of Ideas: The Fate of the Commons in a Connected World. New York: Vintage.

Lury, C. 1993. Cultural Rights: Technology, Legality and Personality. New York: Routledge.

Manovich, L. 2001. The Language of New Media. Cambridge: MIT Press.

Marvin, C. 1988. When Old Technologies Were New: Thinking about Electric Communication in the Late Nineteenth Century. New York: Oxford.

McCourt, T. and P. Burkart 2003. "When Creators, Corporations and Consumers Collide: Napster and the Development of On-line Music Distribution." Media, Culture and Society 25:333-350.

McLeod, K. 2001. Owning Culture: Authorship, Ownership, and Intellectual Property Law. New York: Peter Lang.

McLuhan, M. 1964. Understanding Media: The Extensions of Man. New York: McGraw-Hill.

Miller, P. 2004. Rhythm Science. Cambridge: MIT Press.

Muñoz, L. and J. Healey. 2001. "Pirated Movies Flourish Despite Security Measures." Los Angeles Times,pp. A1,A28.

Negus, K. 1999. Music Genres and Corporate Cultures. New York: Routledge. 
Newman, J. O. 1985. “The Word Made Print: Luther's 1522 New Testament in an Age of Mechanical Reproduction." Representations 11:95-133.

Poschardt, U. 1998. DJ-Culture. London: Quartet Books.

Poster, M. 2001. What's the Matter with the Internet? Minneapolis: University of Minnesota Press.

Rose, M. 1993. Authors and Owners: The Invention of Copyright. Cambridge: Harvard University Press.

Sanjek, R. 1988. American Popular Music and Its Business: The First Four Hundred Years. New York: Oxford University Press.

Schwartz, J. 2004. "A Heretical View of File Sharing." New York Times.

Segrave, K. 1994. Payola in the Music Industry. London: McFarland and Company.
Shemel, S. and W. Krasilovsky 1990. This Business of Music. New York: Watson- Guptill Publications.

Sterne, J. 2003. The Audible Past: Cultural Origins of Sound Reproduction. Durham: Duke University Press.

Thornton, S. 1996. Club Cultures: Music, Media and Subcultural Capital. Hanover: Wesleyan University Press.

Vaidhyanathan, S. 2001. Copyrights and Copywrongs: The Rise of Intellectual Property and How It Threatens Creativity. New York: NYU Press.

Vibe, B. 2004. "Go With the Flow." CTheory 27(1-2).

Wilcox, J. 2003. Where Have All the CDs Gone? Sound \& Vision. 68:87-89. 